\title{
Mandibulada Gelișen Kondroblastik Osteosarkom: Olgu Raporu ve Güncel Literatür ile Karşılaştırılması
} Chondroblastic Osteosarcoma Developing in the Mandible: A Case Report and its Comparison with the Current Literature

\author{
${ }^{1}$ Bedreddin Cavlı, ${ }^{1}$ Onur Odabaşı, ${ }^{2}$ Sibel Elif Gültekin, ${ }^{1}$ Ziver Ergun Yücel
}

${ }^{1}$ Gazi Üniversitesi, Diş hekimliği Fakültesi, Ağız Diş ve Çene Cerrahisi Anabilim Dalı, Ankara, Türkiye ${ }^{2}$ Gazi Üniversitesi, Diş hekimliği Fakültesi, Oral Patoloji Anabilim Dalı, Ankara, Türkiye

\begin{abstract}
Özet: Osteosarkom, çoğu adelosan hastaların uzun kemiklerinde görülen, neoplastik kemik oluşumu ile karakterize malign bir tümördür. Klinik ve radyolojik olarak osteonekroz, fibro-osseöz lezyonlar ile ayırıcı tanılarının yapılması önemlidir. Bu bildiride, mandibulada gömülü diş çevresinde primer olarak gelişen kondroblastik tipte osteosarkom olgusunun, erken ve geç dönem klinik ve radyolojik bulgularının sunumu ve güncel literatürde yayınlanmış benzer vakaların derlenerek paylaşılması amaçlanmaktadır. Ağrı ve dudakta karıncalanma şikayetiyle başvuran hastanın ağız içi muayenesinde diş çekim soketlerinde solid şişlik bulunduğu görülmüş, radyolojik muayenede skleroz ve radyoopak odaklar izlenmiştir. Alınan biyopsi sonucu lezyon histopatolojik olarak kondroblastik tip osteosarkom olarak tanımlanmıştır. Hastaya hemi-mandibulektomi ile eş zamanlı rekonstrüksiyon uygulandı. Hasta 3,5 yıl süresince, 1. yılda nüks nedeniyle tekrar opere edildi, takiplerine devam edilmektedir. Çene kemiklerinde görülen osteosarkomların prognozu her ne kadar uzun kemiklere göre daha iyi olsa da hasta için ciddi morbidite ve mortalite sebebidir, ilk teşhiste dental enfeksiyonlar ile karışabilmektedir. Bu nedenle ciddi radyolojik ve klinik değerlendirme önemlidir.
\end{abstract}

Anahtar Kelimeler: Enfeksiyon, mandibula, osteosarkom, kondroblastik

\begin{abstract}
Osteosarcoma is a malignant tumour characterized by neoplastic bone formation, usually seen in the long bones of adolescent patients. Clinically and radiologically, it is important to make differential diagnosis with osteonecrosis, fibroooseeous lesions. In this report, it is aimed to present a case of chondroblastic type osteosarcoma that developed primarily around the tooth embedded in the mandible, early and late clinical and radiological findings, and to compile and share similar cases published in the current literature. The lesion was defined as chondroblastic type osteosarcoma as a result of biopsy taken from the tooth extraction sockets of the patient who presented with pain and tingling in the lips. The patient underwent simultaneous reconstruction with hemimandibulectomy. Although the prognosis of osteosarcomas seen in the jaw bones is better than the long bones, it is a serious cause of morbidity and mortality for the patient, and may be confused with dental infections in the first diagnosis. Therefore, serious radiological and clinical evaluation is important.
\end{abstract}

Keywords: infection, mandible, osteosarcoma, chondroblastic

ORCID ID of the author: B.C 0000-0002-9935-6351, O.O 0000-0001-7771-048X, S.E.G 0000-0002-0732-3617, Z.E.Y0000-0001-7161-6433 


\section{Giriş}

Sarkomalar kemik, kıkırdak, kas, yağ ve sinir gibi mezenşim kaynaklı hücrelerin malign dönüşümünü ifade eder. Osteosarkoma genellikle adelosan hastalarm uzun kemiklerinde görülür ve osteoid dokuya eșlik eden farklı mezenşimal dokuların malignitesidir. $\% 5$ 'i çene kemiklerinde görülür. Baş boyun bölgesinde sirasıyla en sık mandibula, maksilla ve kalvaryumu etkilemektedir $(1,2)$.

Osteosarkoma tedavi ve prognozda geliştiği bölgeye göre farklı davranışlar sergilemektedir. En s1k konvansiyonel tip osteosarkoma (\%80) görülür. Çene kemiklerinde de konvansiyonel tip yaygindır ancak nadiren de olsa parosteal ve periosteal gelişim görülebilmektedir. Vücutta en sık osteoblastik (\%76) histolojik alt tipi görülürken, çene kemiklerinde ise kondroblastik alt tipi (\%42) yaygındır. (3).

Osteosarkoma, çene-dışı bölgelerde genellikle 2. ve 3. dekatta, çene kemiklerinde ise genellikle 30-40 yaşlarında tanı alır. Erkeklerde hafif oranda (1.35:1) daha fazla görülür. Primer olarak ortaya çıabilse de bilinen birçok risk faktörüne sekonder olarak ortaya çkabilmektedir. Paget hastalarının $\% 5$ 'inde fibröz displazilerin \%1'inde özellikle poliostatik vakalarda görülmektedir. Radyasyonla en sik tetiklenen sarkoma türüdür. 20 gy'in üzerindeki (ortalama 50 gy) radyasyon maruziyetinden, ortalama 11-15 y1l sonra ortaya çıkmaktadır. Radyoterapiye bağlı osteosarkomanın baş boyun bölgesinde görülme riski daha düşüktür. Tümör ayrıca herediter retinoblastom, Werner sendromu, Rothmund-Thomson sendromu ve LiFraumeni sendromu ile ilişkilendirilmiştir (3, 4).

$\mathrm{Bu}$ bildiride, mandibulada gömülü diş çevresinde primer olarak gelişen kondroblastik tipte osteosarkom olgusunun, erken ve geç dönem klinik ve radyolojik bulgularının sunumu amaçlanmaktadır.

\section{Olgu Bildirisi}

29 yaşında kadın hasta, ağrı ve dudakta uyuşukluk şikayetiyle başvurdu. Ağız içi muayenesinde, diş çekim soketlerinde, yüzeyi sağlıklı keratinize dişeti görünümünde solid şişlik bulunduğu tespit edildi. Alınan panoromik radyografta ilgili bölgede skleroz ve radyoopak odaklar izlenmiștir (Resim 1).

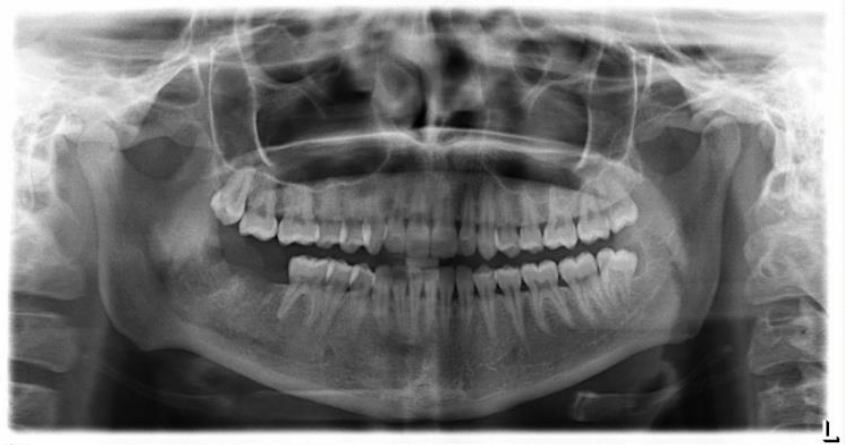

Resim 1. Başvuru sırasında alınan panoromik fillm, 47-48 no'lu diş bölgelerinde RO sklerotik odaklar, yumuşak dokuda ekspansiyon

Hastanın geçmiş filmleriyle birlikte hikayesi dinlenildiğinde, 4 ay önce, aynı şikayetlerin varlığında periodontal cep oluşumuna bağlı enfeksiyon şüphesiyle 20 yaş dişinin çekiminin yapıldı $\breve{g} 1$, şikayetlerin devam etmesi ile 1 ay sonra mobil 47 numaralı dişin de çekiminin yapıldığı öğrenilmiştir. 47 numaralı dişin periodontal aralığının genişlediği, dişin tüm kök çevresinde simetrik olarak y1kılan lamina duranın izlenemediği ve diş çekiminden sonra bulguların şiddetlenmiş olduğu gözlendi (Resim 2-3). 


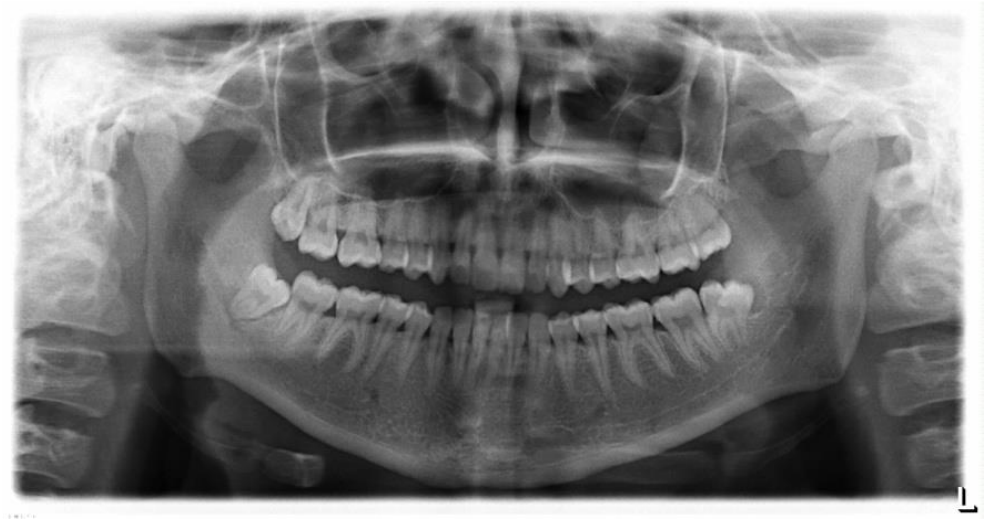

Resim 2. Tanıdan 4 ay önce alınmış olan panoromik radyograf, 47 ve gömülü 48 no'lu diş çevresinde periodontal ligamentlerde aralanma, hafif lamina durada yıkım, kontralaterale göre opasite artışı

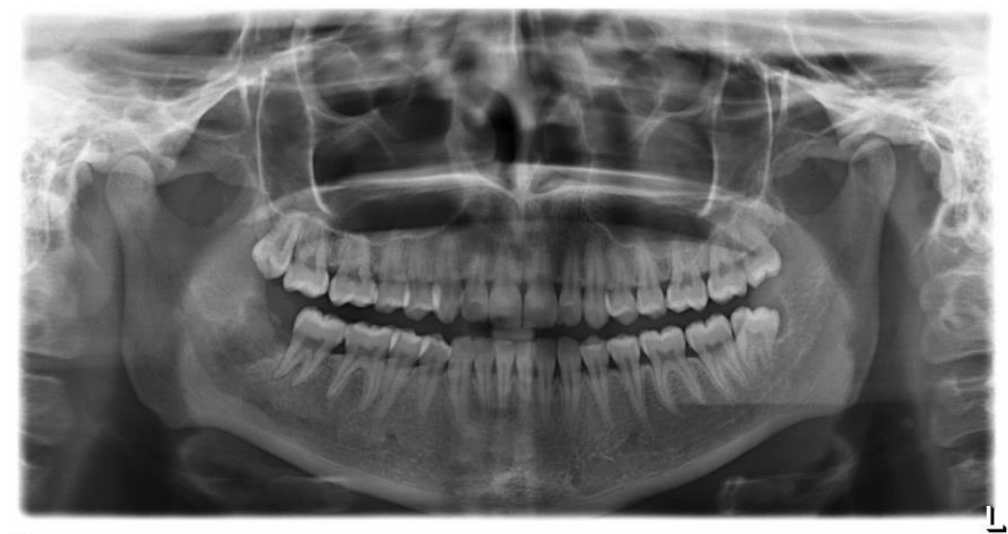

Resim 3. Tanıdan 3 ay önce, 20 yaş diş çekimi sonrası, 47 no'lu diş çevresinde belirginleşen Garrington Belirtisi

Biopsi için bölge açıldığında, solid fibrotik kitle içeren soketlerin formunu koruduğu görülmüştür. Soket histopatolojik inceleme amaciyla kürete edildi ve çevre kemik dokudan örnekler alındı. (Resim 4-5). Alınan biopsi örneği incelenmek üzere G. Ü.
Dişhekimliği Fakültesi Oral Patoloji A.D.'na gönderildi. Materyalin kesitlerinde fokal malign osteoid ve kartilaj oluşumu ile karakterli mezenşimal tümör izlenmiş, lezyon histopatolojik olarak, kondroblastik tip osteosarkom olarak tanımlanmıştır (Resim 6).

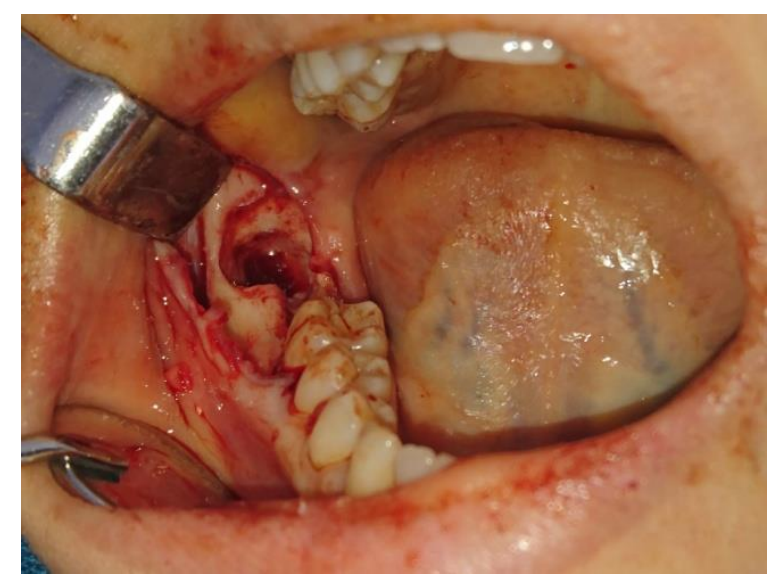

Resim 4. Biopsi operasyonu, retromolar bölgeye uzatılan zarf insizyonla bölgeye ulaşıldı. 47 ve 48 no'lu diş soketlerinin kürete edildikten sonraki durumu 


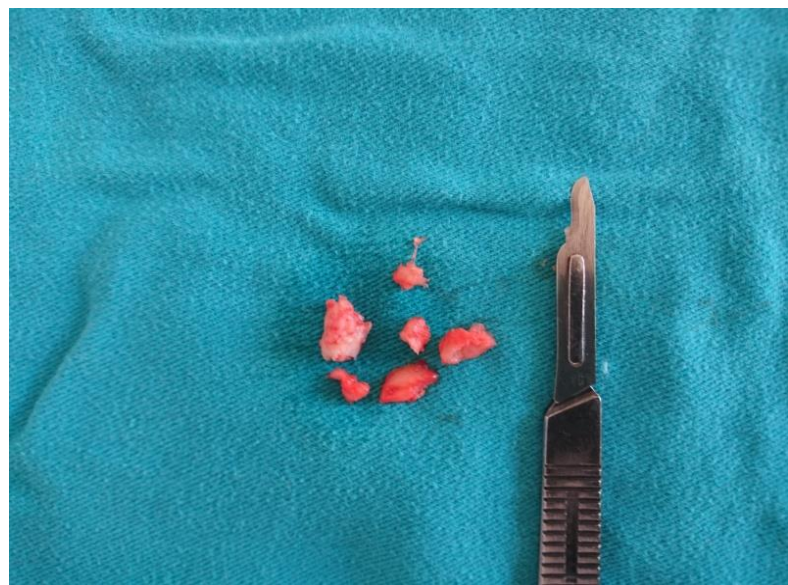

Resim 5. Küretaj materyali

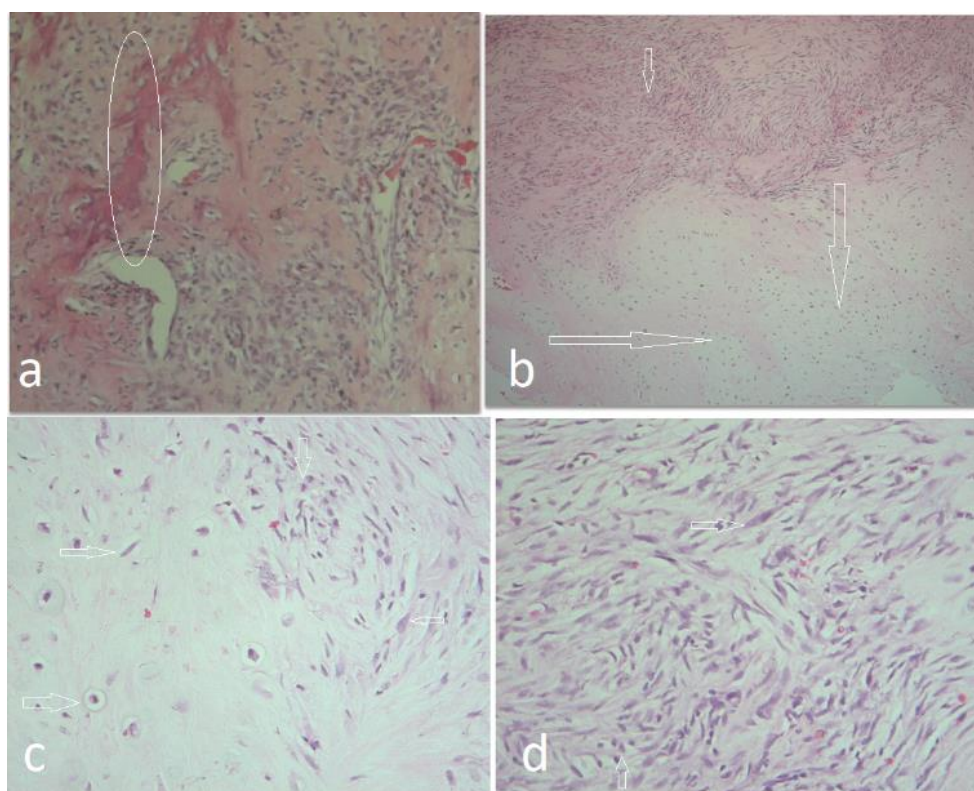

Resim 6. a- İğsi şekilli malign mezenşimal hücreler ve kemik üretim bölgeleri görülmektedir. Tümör adaları içerisindeki bu osseoz patern kondrosarkomla ayırıcı tanıda şarttır, b- Küçük büyütmede iğsi şekilli tümör hücreleri, yoğun mitotik aktivite ve kartilaj doku. c- Büyük büyütmede pleomorfik ve atipik kondroblastlar, d- İğsi şekilli pleomorfik mezenkimal hücreler.

Hastaya Gazi Üniversitesi Tip Fakültesi Kulak Burun Boğaz Anabilim Dalında hemimandibulektomi ile eş zamanlı rekonstrüksiyon uygulandı. Hasta 3,5 yıl süresince, 1. yılda nüks nedeniyle tekrar opere edildi, takiplerine devam edilmektedir.

\section{Tartışma ve Sonuç}

Osteosarkomlarda, klinik ve radyolojik olarak çoğunlukla enfeksiyöz dental problemler ile karıştırılması sonucu, tanı semptomları takiben 2 ile 6 ay içerisinde konulmaktadır. Primer intraosseöz malignitelerde de görülebilen periodontal aralıkta genişleme, sistemik ve lokal çeşitli hastalıklara işaret edebilir. Tüm dişlerin dahil olduğu bir periodontal aralıkta genişleme bruksizmi, troid fonksiyonlarındaki bozukluğu, bifosfonat kullanımını düşündürebilecek iken, izole olarak bir veya birkaç dişteki periodontal aralıkta genişleme akut ve kronik apikal periodontitis, okluzal travma, travmatik okluzyon, ortodontik tedavi sirasinda görülebilmektedir. Bu genişlemenin uniform mu yoksa irregüler mi olduğu, lamina duranın var olup olmadığı oldukça değerlidir. Malign lezyonlar periodontal aralıkta hizla irregüler bir genişleme ve lamina durada yaygın yıkıma 
neden olurlar. $\mathrm{Bu}$ duruma garrington belirtisi denilmektedir $(5,6)$. Vakamızda da bulgular, hastayı ilk gören hekimler tarafindan dental enfeksiyon olarak yorumlanmıştır. Herhangi bir sistemik hastalığ 1 ve ilaç kullanımı olmayan hastanın radyolojik bulguları garrington belirtileri ile birebir uyumlu olduğu görülmektedir.

Radyolojik olarak sınırları belirsiz radyoopak görüntü veren lezyonlar ile ayırıcı tanıları yapılır. Genellikle mandibula posterior bölgede ortaya çıkmaktadır. Hastalar çoğunlukla hızla büyüyen, ağrısız kitle şikayetiyle başvurmaktadır. Ağrı ileri vakalarda görülebilir, hastalar kemik içerisinden gelen derin bir ağrı olarak tarif ederler $(2,3,6)$. Hastamız klinik olarak bize ağrı ile birlikte uyuşukluk şikayetiyle başvurmuş, radyolojik muayenesinde ışınsal olmayan radyoopasite artışı izlenmiştir.

Konvansiyonel osteosarkomun histolojik alt tipleri, kendi aralarında, tedavi ve prognozda farkl1lık göstermemektedir ancak olası benign lezyonlarla ayırıcı tanılarının yapılmasında önem kazanmaktadır. Osteosarkoma; osteoblastoma, kondroblastoma, kondroma, ve fibröz displaziler çok benzer mikroskobik görüntüye sahip olabilmektedir. Dikkat edilmesi gereken nokta hücresel atipi ve yumuşak doku invazyonu varlığıdır. Osteosarkom, hidroksiapatit içeren kollajen fibriller ile Ewing sarkomu, metastatik karsinom, melanom ve lenfomadan ayırt edilir. Kemik üretimi, kondroblastik osteosarkom tanısında, diğer kartilaj patolojilerinin (kondrom, kondroblastom, kondrosarkom) ekarte edilmesinde tanısaldır. Osteosarkomlar genellikle çenelerde görülürken hem kondrosarkom hem de kondrom çoğunlukla kafatabanını etkiler (2, 3). Hastamızın histopatolojik incelemesinde mezenşimal hücrelerin anaplazi ve pleomorfizmi ile birlikte osteoid doku varlığ gösterilmiş, fokal malign osteoid ve kartilaj oluşumu ile karakterli mezenkimal tümör kondroblastik osteosarkoma olarak tanımlanmıştır.

Osteosarkom histopatolojik olarak matriks üreten oldukça pleomorfik osteoblastların (plazmositoid, iğsi, epiteloid) oluşturduğu tümörlerdir. Matriksle çevrilen hücreler genellikle küçülür ve normalleşmiş gibi görünebilir. Bu sebeple neoplaziyi gösteren az miktarda da olsa pleomorfik dönüşüm tanıya götürebilir. Kondroblastik tip hyalin matriks üretir, yüksek derecelidir, çene kemiklerinde en sık görülen osteosarkoma alt tipidir (3).

Sarkomlar nadirdir ancak baş boyun bölgesinin karmaşık anatomisi ve tam rezeksiyon elde etme güçlüğü nedeniyle yüksek morbidite ve mortaliteden sorumludurlar. En iyi sonuçlar neoadjuvan kemoterapi, cerrahi rezeksiyon ve adjuvan kemoterapi ile elde edilmiştir. Ancak vakaların oldukça sınırlı olması nedeniyle çene kemiklerinde kemoterapinin etkinliği henüz netleşmemiştir. Radyoterapi, yalnızca vital dokulara yakın, rezeke edilemeyen vakalar için önerilmiştir. Ancak çene kemiklerinde etkinliği sınırlıdır. Lenf nodu metastazı oldukça nadirdir, klasik tedavide elektif boyun diseksiyonu bulunmamaktadır (4). Tüm anatomik bölgeler göz önüne alındığında, baş ve boyun içinde bir sarkom varlı̆̆1 kendi başına zayıf bir prognostik faktördür ve en yüksek lokal nüks oranları ve hastalığa özgü en kötü sağkalım ile ilişkilidir $(7,8)$.

Prognozda en önemli etken cerrahi sinır ve tümörün derecesidir. Negatif cerrahi marjini elde edilen hastalar için \%75 sağkalım oranından bahsedilebilirken, rezidüel tümör varlığında bu oran \%32'ye gerilemektedir. 5 yıllık sağkalım düşük dereceli tümörlerde \%74 iken yüksek dereceli tümörlerde \%42'dir. Çene kemiklerinde, rezeke edilebilme kolaylığı nedeniyle, anterior mandibulada en iyi prognoza sahip iken, maksilla anterior en kötü prognozu gösteren bölgededir $(2,4)$.

Baş boyun kanserlerinde sağkalım oranı ve hayat kalitesi, doğrudan tümörün ilk teşhisi sırasında ulaştığı boyutlar ile ilişkilidir ancak osteosarkom gibi hızlı ve agresif davranışlar gösteren, teşhis için gerekli kriterleri spesifik özellik göstermeyen maligniteler, erken tanıya neredeyse imkân vermemektedir. Bu nedenle hekimlerin radyolojik ve klinik değerlendirmelerinde göstereceği dikkat erken tanıda önem taşımaktadır. 


\section{KAYNAKLAR}

1. de Carvalho WRS, de Souza LL, Pontes FSC, et al. A multicenter study of oral sarcomas in Brazil. Oral Diseases 2020;26:43-52.

2. Kyle S, Ettinger KA. Sarcomas of the Jaws. In: Fonseca RJ (ed) Oral and Maxillofacial Surgery, Volume 2, Third Edition. 2018, pp.643-669.

3. Fletcher CDM, Bridge JA, Hogendoorn P, Mertens F. WHO Classification of Tumours of Soft Tissue and Bone. Fourth Edition. 2013, pp.282 296

4. Shah JP, Patel SG, Singh B, Wong R. Bone Tumors and Odontogenic Lesions. Jatin Shah's Head And Neck Surgery And Oncology, Fifth Edition. 2020, pp.701 - 753.

5. Fernandes R, Nikitakis NG, Pazoki A, Ord RA Osteogenic Sarcoma of the Jaw: A 10-Year Experience. J Oral Maxillofac Surg. 2007;65: 1286-91.

6. Gadwal SR, Gannon FH, Fanburg-Smith JC, Becoskie M, Thompson LD. Primary osteosarcoma of the head and neck in pediatric patients: a clinicopathologic study of 22 cases with a review of the literature. Cancer 2001;91: 598-605.

7. Van den Berg H, Schreuder W, De Lange J. Osteosarcoma: a comparison of jaw versus nonjaw localizations and review of the literature. Sarcoma 2013; 2013:316123.

8. Wagh A, Kokane G, Jendi S, Khatib S, Mistry J, Vaidya K. Early Diagnosis: A Seeming Misfortune for Osteosarcoma of Mandible-Rare Case Report. Indian J Otolaryngol Head Neck Surg. 2019;71:748-51. 